\title{
Morphological Analysis and Interaction of Chlorophyll and BSA
}

\author{
Filipe D. S. Gorza, Graciela C. Pedro, Tarquin F. Trescher, Romário J. da Silva, \\ Josmary R. Silva, and Nara C. de Souza
}

Grupo de Materiais Nanoestruturados, Universidade Federal de Mato Grosso, 78600-000 Barra do Garças, MT, Brazil

Correspondence should be addressed to Nara C. de Souza; ncsouza@ufmt.br

Received 27 February 2014; Revised 21 April 2014; Accepted 21 April 2014; Published 18 May 2014

Academic Editor: Rumiana Koynova

Copyright (C) 2014 Filipe D. S. Gorza et al. This is an open access article distributed under the Creative Commons Attribution License, which permits unrestricted use, distribution, and reproduction in any medium, provided the original work is properly cited.

\begin{abstract}
Interactions between proteins and drugs, which can lead to formation of stable drug-protein complexes, have important implications on several processes related to human health. These interactions can affect, for instance, free concentration, biological activity, and metabolism of the drugs in the blood stream. Here, we report on the UV-Visible spectroscopic investigation on the interaction of bovine serum albumin (BSA) with chlorophyll (Chl) in aqueous solution under physiological conditions. Binding constants at different temperatures-obtained by using the Benesi-Hildebrand equation-were found to be of the same order of magnitude $\left(\sim 10^{4} \mathrm{M}^{-1}\right)$ indicating low affinity of Chl with BSA. We have found a hyperchromism, which suggested an interaction between BSA and Chl occurring through conformational changes of BSA caused by exposition of tryptophan to solvent. Films from BSA and Chl obtained at different Chl concentrations showed fractal structures, which were characterized by fractal dimension calculated from microscopic image analysis.
\end{abstract}

\section{Introduction}

Binding of human serum protein (HSA) with different compounds has been an intense research field in chemistry, biology, and medicine. Processes such as absorption, excretion, and toxicity of drugs, for instance, during chemotherapy [1] can be affected by the binding of these compounds with HSA $[2,3]$. Several investigations from experimental and theoretical [4-7] viewpoints on the binding of HSA with drugs have been performed. Some used drugs were $3^{\prime}$-azido$3^{\prime}$-deoxythymidine (AZT), aspirin, taxol, cisplatin, atrazine, 2,4-dichlorophenoxyacetic (2,4-D), polyamines, chlorophyll, chlorophyllin, poly(ethylene glycol), vanadyl cation, vanadate anion, cobalt-hexamine, and arsenic trioxide $\left(\mathrm{As}_{2} \mathrm{O}_{3}\right)$, astilbin [8].

An alternative to the HSA is the bovine serum albumin (BSA), which has been used as a model of proteins for the study of biophysical and physicochemical processes. BSA is very attractive because it has low cost, stability, structural homology of $80 \%$ with HSA, water solubility, and versatile binding ability [9]. A lot of studies on interaction of BSA and ligands have been carried out. In these works, compounds including 2-(4-N,N-dimethylamino) phenylimidazo [4,5b]pyridine (DMAPIP-b) [10], imidazolium chloride ionic liquids [11], prednisolone [12], aspirin [13], resveratrol [14], genistein [14], curcumin [14-16], malachite Green [17], bright red 6C [18], anticancer drugs [19], heparin [20], and ascorbic acid [21] were used. In particular, the behavior of the binding of chlorophyll (Chl) to BSA has been also examined [22] because it has been shown that this ligand can exhibit antimutagenic property against several potential human carcinogens $[23,24]$, action antioxidant [25], and antigenotoxic [26]. It is considered as a drug due to its bactericidal activity and high performance healing of wounds in addition to acting as an antioxidant in burns [27]. It has also been used as a photosensitizer for photodynamic therapy drug for its high absorptivity in the visible light region of the electromagnetic spectrum and low toxicity. Despite these studies, interaction of BSA and Chl by analysis of casting films from these compounds has not been carried out yet. Therefore, studying the interaction of Chl with BSA in aqueous solution and solid state (as films) can be used as a model for elucidating the Chl-HSA complex. Chl can bind to biological proteins modulating their activities. This bind process is determined 
by the behavior of interactions between drugs with proteins [21]. To the best of our knowledge, there have been no studies on interaction between $\mathrm{Chl}$ and proteins in casting films.

In this paper, we report on the study of interaction between $\mathrm{Chl}$ and BSA in aqueous solution by using UVVis spectroscopy, which allowed the determining of the binding constants at different temperatures. In addition, casting films were prepared from BSA and Chl in whichby using optical microscopy-the morphological structures found were studied.

\section{Materials and Methods}

Chlorophyll (MP Biomedicals) and BSA (fraction V, purity 96-100\%) from Acros Organics were used as received. Chl stock solution was prepared by dissolving $\mathrm{Chl}$ in purified water with a concentration of $5.5 \times 10^{-4} \mathrm{~mol} \cdot \mathrm{L}^{-1}\left(0.5 \mathrm{~g} \cdot \mathrm{L}^{-1}\right)$. The $\mathrm{pH}$ of the Chl solution was adjusted to 8 (close to physiologic $\mathrm{pH}$ ) by adding appropriate amounts of ammonium hydroxide. BSA stock solution was obtained by dissolving the BSA in PBS buffer, physiological pH, with a concentration of $7.6 \times 10^{-6} \mathrm{~mol} \cdot \mathrm{L}^{-1}\left(0.5 \mathrm{~g} \cdot \mathrm{L}^{-1}\right)$. Solutions at concentrations below were obtained from stock solutions. The films were prepared by casting $100 \mu \mathrm{L}$ of solutions on a quartz slice $(36.0 \mathrm{~mm} \times 14.0 \mathrm{~mm} \times 1.0 \mathrm{~mm})$. The adsorbed amount, which is proportional to absorbance, was monitored by measuring the UV-Vis absorption spectra with a double-beam Thermo Scientific spectrophotometer model GENESYS 10. Surface morphological structure was investigated by using an optical microscope (model Eclipse $\mathrm{Ci} / \mathrm{L}$, Nikon). ImageJ software [28] was employed to determine the fractal dimension using the box counting method.

\section{Results and Discussion}

3.1. Study of Solutions. Figure 1 displays the spectra of BSA and Chl solutions as well as the spectra of the films and mixing of solutions. For BSA solution, it is possible to note a typical absorption peak at $278 \mathrm{~nm}$, which is attributed to tryptophan amino acid and tyrosine [29]. In contrast to Chl in solution ( $404 \mathrm{~nm}$ ), the absorption peak of Chl films appears at $408 \mathrm{~nm}$. These results reveal a red shift of $4 \mathrm{~nm}$ for the film in relation to aqueous solution. According to the exciton theory, this shift indicates the occurrence of aggregation [30]. It is well known that when the dye molecules in the solution phase are transferred to a solid surface, molecular aggregation may occur [31].

The UV-Vis spectroscopy technique is a simple and effective method to investigate the molecular interaction and complex formation [21]. UV-Vis analyses were performed for $\mathrm{BSA}$ in solution with physiological $\mathrm{pH}$ and concentration of $1.9 \times 10^{-6} \mathrm{~mol} \cdot \mathrm{L}^{-1}$ (required for better visualization of the band at $278 \mathrm{~nm}$ ) and modified solution after the addition of $\mathrm{Chl}$ at different concentrations. All of these experiments were carried out using $2.0 \mathrm{~mL}$ of BSA solution contained in a quartz cuvette. The amount of $\mathrm{Chl}$ added was the same $(40 \mu \mathrm{L})$ for all concentrations examined $(1.1,2.2,3.3,4.4,5.5$, and $\left.6.6 \times 10^{-5} \mathrm{~mol} \cdot \mathrm{L}^{-1}\right)$. The experiment was repeated in

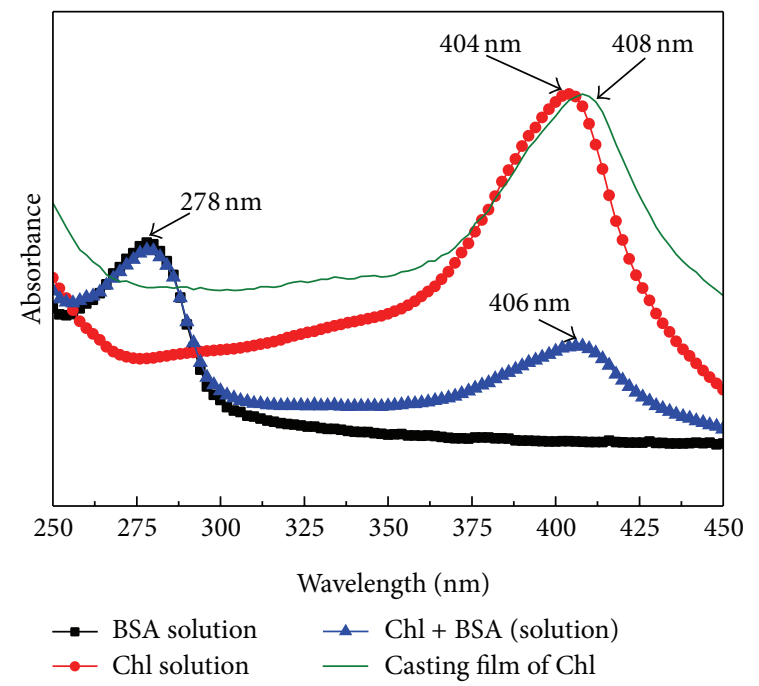

FIGURE 1: Spectra of BSA, Chl, BSA + Chl solutions, and Chl casting film at $23^{\circ} \mathrm{C}$.

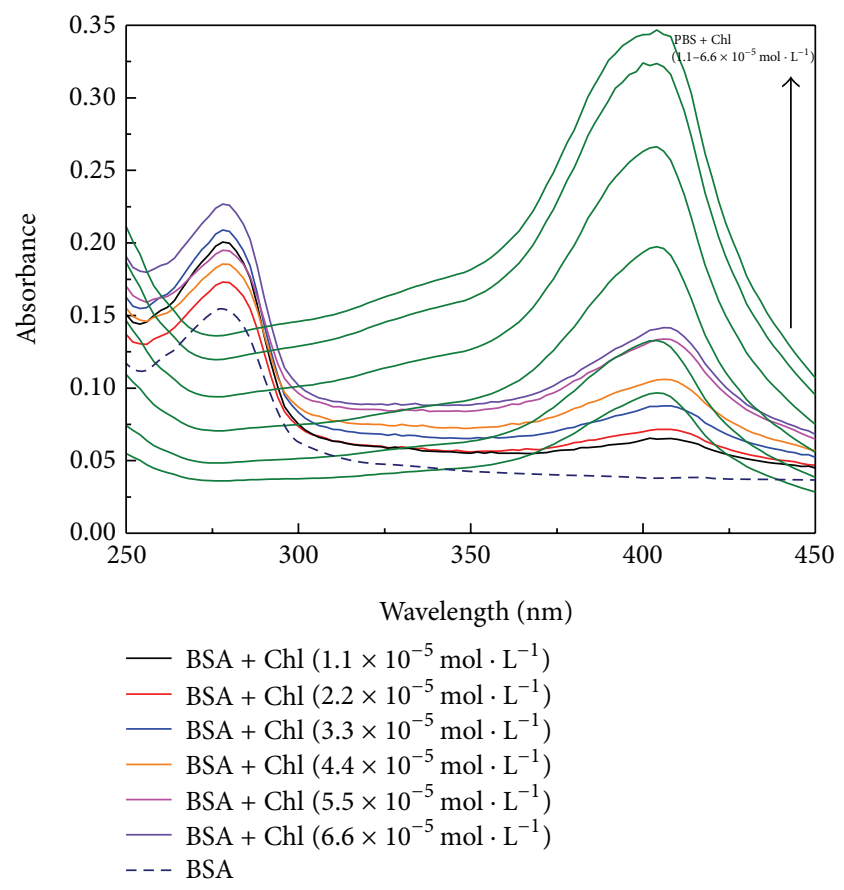

FIGURE 2: Spectra of BSA solution before (- - ) and after addition of $\mathrm{Chl}$ at different concentrations. The green spectra are the Chl at different concentrations in PBS solution without BSA.

PBS solution without BSA (green curves in Figure 2). This procedure aims to discard the effect of absorption of Chl. The difference between the spectra with and without BSA reveals the behavior of the BSA front of Chl.

Figure 2 shows the UV-Vis spectra for BSA solution (dot curve) and BSA with aliquot of $40 \mu \mathrm{L}$ of $\mathrm{Chl}$ at different concentrations. The green spectra are aliquot of $\mathrm{Chl}$ at different concentration with PBS solution. Hyperchromism effect was observed with increasing Chl concentration in BSA. This effect can be associated with the interaction of BSA 


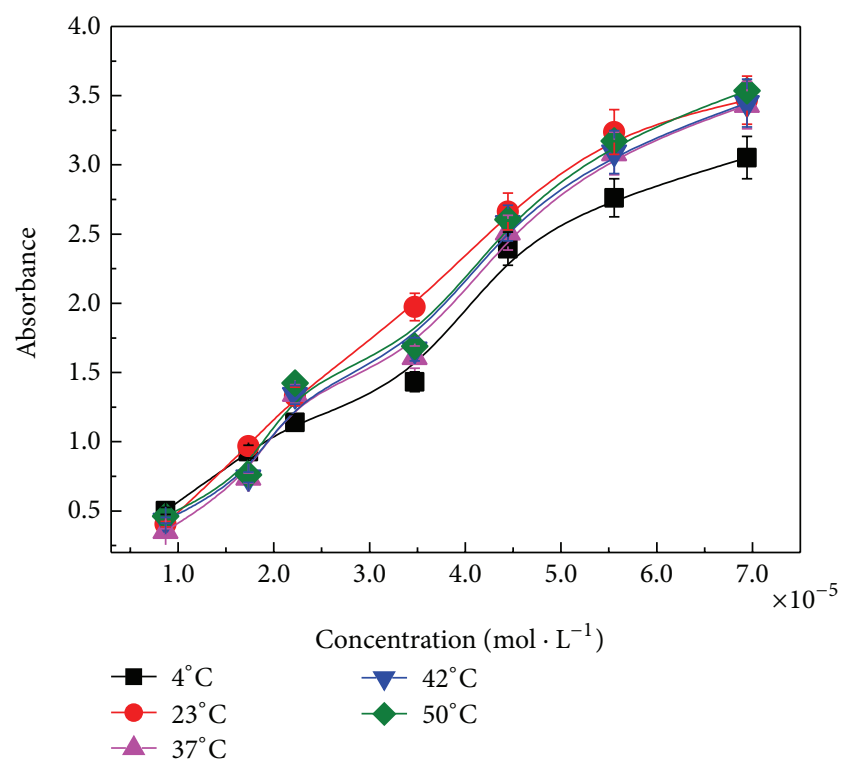

Figure 3: Absorbance versus concentration of Chl obtained at different temperatures. The curves were evaluated at $278 \mathrm{~nm}$.

with Chl and may be indicative of an increase in exposure of tryptophan to the solvent $[21,32]$ due to a conformational change in the protein [33].

Figure 3 shows a plot of absorbance as a function of Chl concentration at different temperatures. No great differences are observed by changing the temperature, but it is noted that the absorbance increases with increasing $\mathrm{Chl}$ concentration. As discussed above, this hyperchromism may indicate an interaction between BSA and Chl [33-35].

3.2. Determination of Binding Constants. The determination of binding constant of Chl with BSA was determined by using a double reciprocal plot, which was obtained in terms of absorbance changes at $278 \mathrm{~nm}$ as a function of reciprocal concentration according to the Benesi-Hildebrand equation $[16,34]$ :

$$
\frac{1}{\Delta A_{\mathrm{abs}}}=\frac{1}{[S][L] \varepsilon K}+\frac{1}{[S] \varepsilon},
$$

where $\Delta A_{\mathrm{abs}}$ is the change in the absorbance at $278 \mathrm{~nm}, K$ is the binding constant, $[S]$ is the concentration of BSA, $[L]$ is the concentration of $\mathrm{Chl}$, and $\varepsilon$ is the extinction coefficient.

Figure 4 shows the linear plots of $1 / \Delta A_{\text {abs }}$ versus $1 /[\mathrm{Chl}]$ for aqueous solution of BSA and $\mathrm{Chl}$ at 23,37 , and $42^{\circ} \mathrm{C}$. They were obtained by changing the $\mathrm{Chl}$ concentration as shown in Figures 2 and 3.

The changes in absorbance values were followed at $278 \mathrm{~nm}$. The binding constants have been estimated to be $K \sim$ $10^{4} \mathrm{M}^{-1}$ for all the temperatures used. This value is similar to that found in literature for HSA-Chl complexes [2, 3]. Values of the binding constant in the range $1-15 \times 10^{4} \mathrm{M}^{-1}$ are considered moderate [36]. In this case, absorption and distribution of drugs for tissues are feasible. Then, our results suggest that even for temperatures of 23 and $42^{\circ} \mathrm{C}$,
TABLE 1: Fractal dimension values for the films prepared from BSA and $\mathrm{Chl}$ at 23 and $37^{\circ} \mathrm{C}$ at different concentrations.

\begin{tabular}{lcc}
\hline $\begin{array}{l}\text { Conc. } \\
\mathrm{Chl}\left(\mathrm{mol} \cdot \mathrm{L}^{-1}\right)\end{array}$ & $\begin{array}{c}\mathrm{Chl}+\mathrm{BSA} \\
23^{\circ} \mathrm{C}\end{array}$ & $\begin{array}{c}\mathrm{Chl}+\mathrm{BSA} \\
37^{\circ} \mathrm{C}\end{array}$ \\
\hline $3.3 \times 10^{-5}$ & 1.25 & 1.31 \\
$6.6 \times 10^{-5}$ & 1.27 & 1.33 \\
$1.4 \times 10^{-4}$ & 1.37 & 1.50 \\
$5.5 \times 10^{-4}$ & 1.65 & 1.62 \\
\hline
\end{tabular}

which means hypothermia and fever for human body, the absorption and distribution of $\mathrm{Chl}$ for tissues are available.

3.3. Morphological Analysis. Figure 5 shows optical microscopic images for films from BSA + Chl at different concentrations of Chl. We note fractal structures for all of the Chl concentrations used. Films from pure BSA do not exhibit fractal structures, whereas those prepared from pure Chl exhibit several fractals (data not shown). Fractals have branched structures; however, larger branches are observed in films obtained at $37^{\circ} \mathrm{C}$. The difference between the values of Df (fractal dimension) for casting films obtained at different temperatures can be related to the procedure and the time required for drying, since dry films at $37^{\circ} \mathrm{C}$ were prepared in an oven while others were obtained at room temperature.

In order to gain an insight in formation mechanism of the fractal structures, the concept of fractal dimension was used to characterize fractal structures $[37,38]$. We have determined the fractal dimensions of the structures by using the box counting method [39]. Table 1 displays the fractal dimensions from Figure 5. It is noted that the fractal dimension increases as function of concentration. This arises from the increase in size of fractal structures. Special attention should be paid to $D_{f} \sim 1.6$, which was obtained from the fractal structures at concentration of $5.5 \times 10^{-4} \mathrm{~mol} \cdot \mathrm{L}^{-1}$. This value is close to $D_{f}=1.7$, predicted for the diffusion-limited aggregation (DLA) model $[39,40]$. This result is consistent with the aggregation suggested by the finds using UV-Vis spectroscopy (Figure 1) and suggests the complex formation of BSA with Chl.

\section{Conclusion}

We have investigated the interaction of BSA with Chl in aqueous solution as well as the morphological structures formed in films from these two compounds. Albumins promote the transport of material in the blood and are able to bind with different biologically active compounds, such as drugs, steroids, and dyes. As only free drug can exert their action, some factors influence their effectiveness in the active site. One such factor is the affinity of the protein drug which can be measured by the binding constant between them. The binding constant was found to be stable around $10^{4} \mathrm{M}^{-1}$ for all temperatures employed. This indicates a moderate affinity between BSA and Chl, which is suitable to absorption 


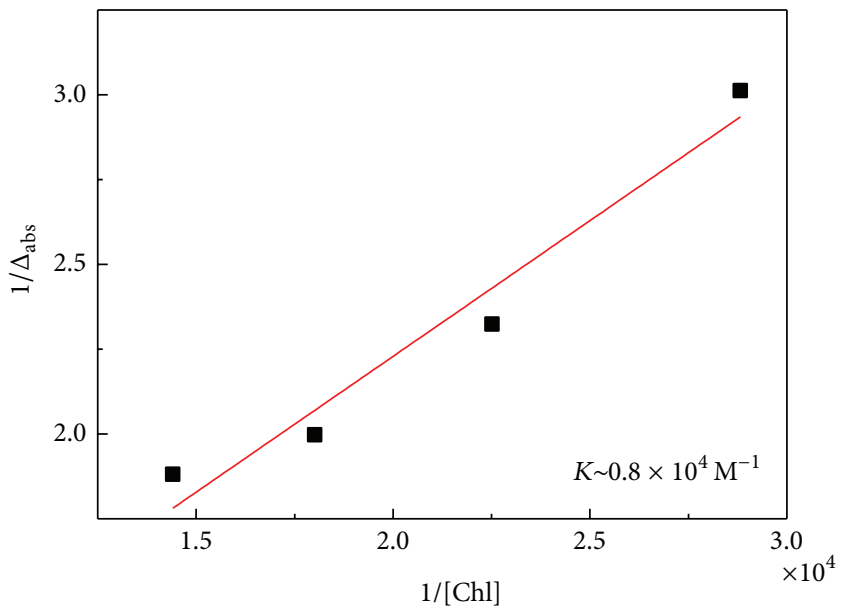

$23^{\circ} \mathrm{C}$

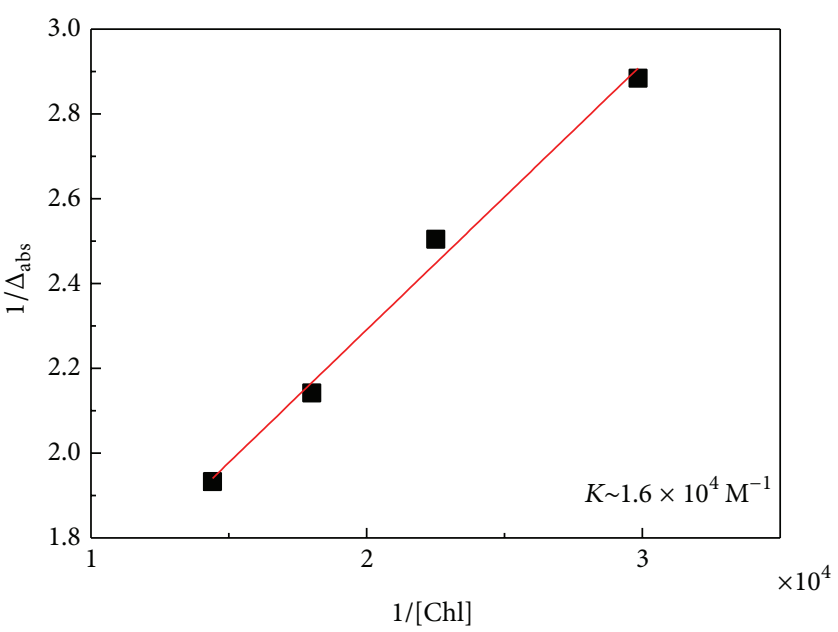

- $37^{\circ} \mathrm{C}$

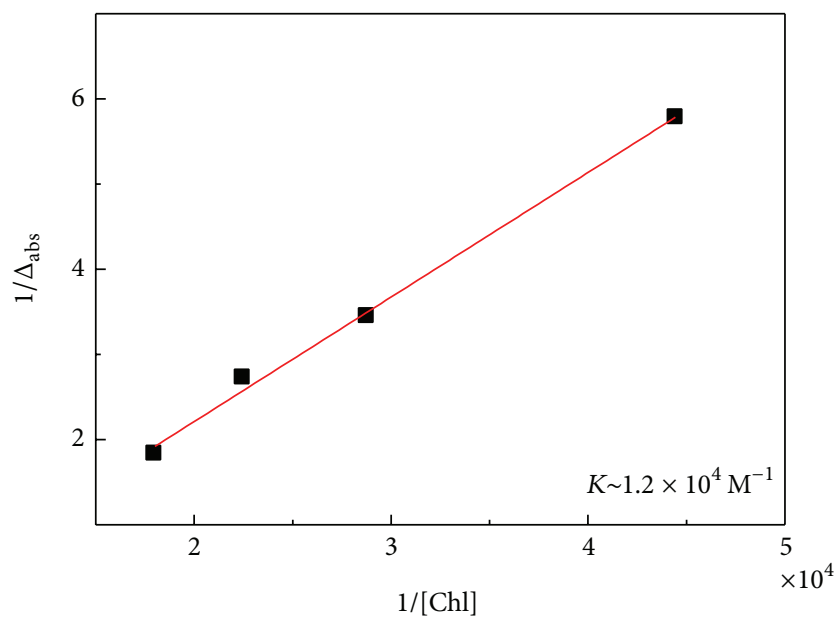

$42^{\circ} \mathrm{C}$

FIGURE 4: Linear plots for $1 / \Delta A_{\text {abs }}$ versus $1 /[\mathrm{Chl}]$ at 23,37 , and $42^{\circ} \mathrm{C}$. 


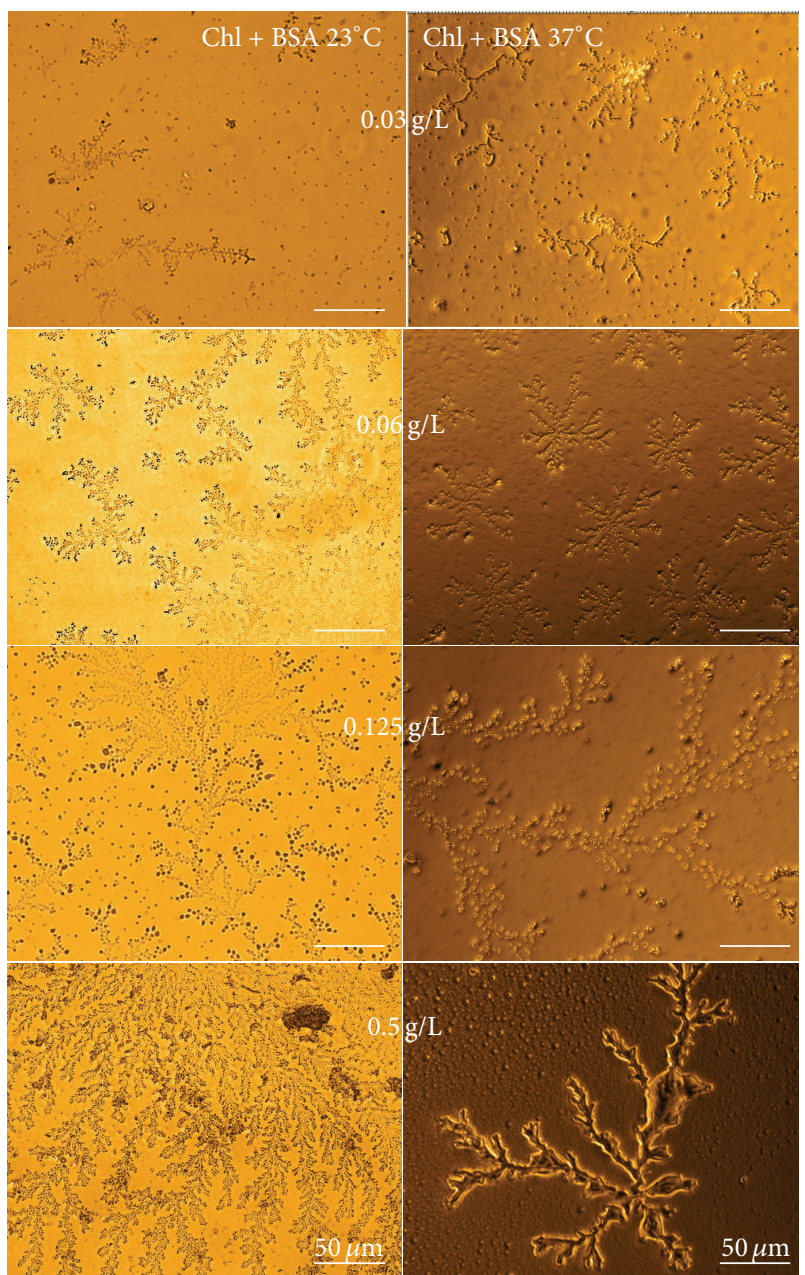

Figure 5: Optical microscopic images of films from BSA + Chl at 23 and $37^{\circ} \mathrm{C}$ at different $\mathrm{Chl}$ concentrations.

and transportation of this compound. It revealed a hyperchromism indicating an interaction of BSA and Chl, which can occur through conformational change of BSA caused by exposition of tryptophan to solvent. Films from BSA show that fractal dimension depends on concentration which is associated with the increase of size of the structures. At concentration of $5.5 \times 10^{-4} \mathrm{~mol} \cdot \mathrm{L}^{-1}$, the fractal dimension is found to be $D_{f} \sim 1.6$, which is close to $D_{f}=1.7$ predicted for the diffusion-limited aggregation (DLA) model. Alternative methods such as microscopy and fractal analysis may lead to relevant insights into the interactions which occur between HSA with Chl in human body.

\section{Conflict of Interests}

The authors declare that there is no conflict of interests regarding the publication of this paper.

\section{Acknowledgments}

The authors thank CNPq and CAPES (Brazil) for the financial support.

\section{References}

[1] R. E. Olson and D. D. Christ, "Plasma protein binding of drugs," Annual Reports in Medicinal Chemistry, vol. 31, pp. 327-336, 1996.

[2] H. A. Tajmir-Riahi, "An overview of drug binding to human serum albumin: protein folding and unfolding," Scientia Iranica, vol. 14, no. 2, pp. 87-95, 2007.

[3] A. A. Ouameur, R. Marty, and H. A. Tajmir-Riahi, "Human serum albumin complexes with chlorophyll and chlorophyllin," Biopolymers, vol. 77, no. 3, pp. 129-136, 2005.

[4] Q. Yang, X. Zhou, and X. Chen, "Combined molecular docking and multi-spectroscopic investigation on the interaction between Eosin B and human serum albumin," Journal of Luminescence, vol. 131, no. 4, pp. 581-586, 2011.

[5] M. Bardhan, J. Chowdhury, and T. Ganguly, "Investigations on the interactions of aurintricarboxylic acid with bovine serum albumin: steady state/time resolved spectroscopic and docking studies," Journal of Photochemistry and Photobiology B: Biology, vol. 102, no. 1, pp. 11-19, 2011.

[6] Y. Li, Y. Ge, Y. Zhang et al., "Interaction of coomassie brilliant blue G250 with human serum albumin: probing of the binding mechanism and binding site by spectroscopic and molecular modeling methods," Journal of Molecular Structure, vol. 968, no. $1-3$, pp. 24-31, 2010.

[7] P. Daneshgar, A. A. Moosavi-Movahedi, P. Norouzi, M. R. Ganjali, A. Madadkar-Sobhani, and A. A. Saboury, "Molecular interaction of human serum albumin with paracetamol: spectroscopic and molecular modeling studies," International Journal of Biological Macromolecules, vol. 45, no. 2, pp. 129-134, 2009.

[8] J. Wang, S. Li, X. Peng et al., "Multi-spectroscopic studies on the interaction of human serum albumin with astilbin: binding characteristics and structural analysis," Journal of Luminescence, vol. 136, pp. 422-429, 2013.

[9] N. C. de Souza, J. C. J. Flores, and J. R. Silva, "Layer-bylayer films from tartrazine dye with bovine serum albumin," Chemical Physics Letters, vol. 484, no. 1-3, pp. 33-36, 2009.

[10] N. Dash, A. Mishra, and G. Krishnamoorthy, "Alkyl chain dependent interactions of ligands with bovine serum albumin," Journal of Pharmaceutical and Biomedical Analysis, vol. 77, pp. 55-62, 2013.

[11] R. Huang, S. Zhang, L. Pan, J. Li, F. Liu, and H. Liu, "Spectroscopic studies on the interactions between imidazolium chloride ionic liquids and bovine serum albumin," Spectrochimica Acta A: Molecular AndBiomolecular Spectroscopy, vol. 104, pp. 377-382, 2013.

[12] J. H. Shi, Y. Y. Zhu, J. Wang, J. Chen, and Y. J. Shen, "Intermolecular interaction of prednisolone with bovine serum albumin: spectroscopic and molecular docking methods," Spectrochimica Acta A: Molecular and Biomolecular Spectroscopy, vol. 103, pp. 287-294, 2013

[13] S. Nafisi, G. Bagheri Sadeghi, and A. Panahyab, "Interaction of aspirin and vitamin $\mathrm{C}$ with bovine serum albumin," Journal of Photochemistry and Photobiology B: Biology, vol. 105, no. 3, pp. 198-202, 2011.

[14] P. N. P. Bourassa, C. D. Kanakis, P. Tarantilis, M. G. Pollissiou, and H. A. Tajmir-Riahi, "Resveratrol, genistein, and curcumin bind bovine serum albumin," Journal of Physical Chemistry B, vol. 114, no. 9, pp. 3348-3354, 2010. 
[15] S. P. Mitra, "Binding and stability of curcumin in presence of bovine serum albumin," Journal of Surface Science and Technology, vol. 23, no. 3-4, pp. 91-110, 2007.

[16] Barik, K. I. Priyadarsini, and H. Mohan, "Photophysical studies on binding of curcumin to bovine serum albumin," Photochemistry and Photobiology, vol. 77, no. 6, pp. 597-603, 2003.

[17] Y. Zhang, B. Zhou, X. Zhang, P. Huang, C. Li, and Y. Liu, "Interaction of malachite green with bovine serum albumin: determination of the binding mechanism and binding site by spectroscopic methods," Journal of Hazardous Materials, vol. 163, no. 2-3, pp. 1345-1352, 2009.

[18] J. Sereikaite, Z. Bumeliene, and V.-A. Bumelis, "Bovine serum albumin-dye binding," Acta Chromatographica, no. 15, pp. 298307, 2005.

[19] S. Bakkialakshmi and D. Chandrakala, "A spectroscopic investigations of anticancer drugs binding to bovine serum albumin," Spectrochimica Acta A: Molecular and Biomolecular Spectroscopy, vol. 88, pp. 2-9, 2012.

[20] T. Hattori, K. Kimura, E. Seyrek, and P. L. Dubin, "Binding of bovine serum albumin to heparin determined by turbidimetric titration and frontal analysis continuous capillary electrophoresis," Analytical Biochemistry, vol. 295, no. 2, pp. 158-167, 2001.

[21] R. R. G. Maciel, A. A. de Almeida, O. G. C. Godinho et al., "Ascorbic acid and BSA protein in solution and films: interaction and surface morphological structure," BioMed Research International, vol. 2013, Article ID 461365, 7 pages, 2013.

[22] H. Shibata, H. Ochiai, T. Kawashima, T. Okamoto, and I. Inamura, "Preparation and properties of the water-soluble chlorophyll-bovine serum albumin complexes," $B B A-$ Bioenergetics, vol. 852, no. 2-3, pp. 175-182, 1986.

[23] S. W. Kimm and S. C. Park, "Evidences for the existence of antimutagenic factors in edible plants," Korean Journal of Biochemistry, vol. 14, no. 2, pp. 47-59, 1982.

[24] T. Ong, W. Z. Whong, J. Stewart, and H. E. Brockman, "Chlorophyllin: a potent antimutagen against environmental and dietary complex mixtures," Mutation Research, vol. 173, no. 2, pp. 111-115, 1986.

[25] M. G. Ferruzzi, V. Böhm, P. D. Courtney, and S. J. Schwartz, "Antioxidant and antimutagenic activity of dietary chlorophyll derivatives determined by radical scavenging and bacterial reverse mutagenesis assays," Journal of Food Science, vol. 67, no. 7, pp. 2589-2595, 2002.

[26] G. C. Bez, B. Q. Jordão, V. E. P. Vicentini, and M. S. Mantovani, "Investigation of genotoxic and antigenotoxic activities of chlorophylls and chlorophyllin in cultured V79 cells," Mutation Research-Genetic Toxicology and Environmental Mutagenesis, vol. 497, no. 1-2, pp. 139-145, 2001.

[27] B. M. Dorvigny, L. M. S. Perera, S. D. Aguirre et al., "Healing effect of Pinus caribaea var. caribaea paste on aseptic open wounds," Revista Cubana de Plantas Medicinales, vol. 16, no. 1, pp. 24-33, 2011.

[28] C. A. Schneider, W. S. Rasband, and K. W. Eliceiri, "NIH Image to Image J: 25 years of image analysis," Nature Methods, vol. 9, no. 7, pp. 671-675, 2012.

[29] D. Gao, Y. Tian, F. Liang et al., "Investigation on the pHdependent binding of Eosin $\mathrm{Y}$ and bovine serum albumin by spectral methods," Journal of Luminescence, vol. 127, no. 2, pp. 515-522, 2007.

[30] M. C. Petty, Langmuir-Blodgett Films: An Introduction, Cambridge University Press, 1st edition, 1996.
[31] J. B. Brito, D. J. C. Gomes, V. D. Justina et al., "Nanostructured films from phthalocyanine and carbon nanotubes: surface morphology and electrical characterization," Journal of Colloid and Interface Science, vol. 367, no. 1, pp. 467-471, 2012.

[32] P. Daneshegar, A. A. Moosavi-Movahedi, P. Norouzi, M. R. Ganjali, M. Farhadic, and N. Sheibani, "Characterization of paracetamol binding with normal and glycated human serum albumin assayed by a new electrochemical method," Journal of the Brazilian Chemical Society, vol. 23, no. 2, pp. 315-321, 2012.

[33] R. S. Kumar, P. Paul, A. Riyasdeen et al., "Human serum albumin binding and cytotoxicity studies of surfactant-cobalt(III) complex containing 1,10-phenanthroline ligand," Colloids and Surfaces B: Biointerfaces, vol. 86, no. 1, pp. 35-44, 2011.

[34] I. D. Kuntz Jr., F. P. Gasparro, M. D. Johnston Jr., and R. P. Taylor, "Molecular interactions and the Benesi-Hildebrand equation," Journal of the American Chemical Society, vol. 90, no. 18, pp. 4778-4781, 1968.

[35] K. A. Connors, Binding Constants: The Measurement of Molecular Complex Stability, Wiley-Interscience, New York, NY, USA, 1st edition, 1987.

[36] S. Naveenraj and S. Anandan, "Binding of serum albumins with bioactive substances-nanoparticles to drugs," Journal of Photochemistry and Photobiology C: Photochemistry Reviews, vol. 14, pp. 53-71.

[37] A. L. Barabási and H. E. Stanley, Fractal Concepts in Surface Growth, Cambridge University Press, 1st edition, 1995.

[38] N. C. de Souza, J. R. Silva, C. A. Rodrigues, L. D. F. Costa, J. A. Giacometti, and O. N. Oliveira Jr., "Adsorption processes in layer-by-layer films of poly(o-methoxyaniline): the role of aggregation," Thin Solid Films, vol. 428, no. 1-2, pp. 232-236, 2003.

[39] L. Ottaviano, P. Parisse, V. Grossi, and M. Passacantando, "Nanowire directed diffusion limited aggregation growth of nanoparticles," Journal of Non-Crystalline Solids, vol. 356, no. 37-40, pp. 2076-2078, 2010.

[40] T. A. Witten Jr. and L. M. Sander, "Diffusion-limited aggregation, a kinetic critical phenomenon," Physical Review Letters, vol. 47, no. 19, pp. 1400-1403, 1981. 

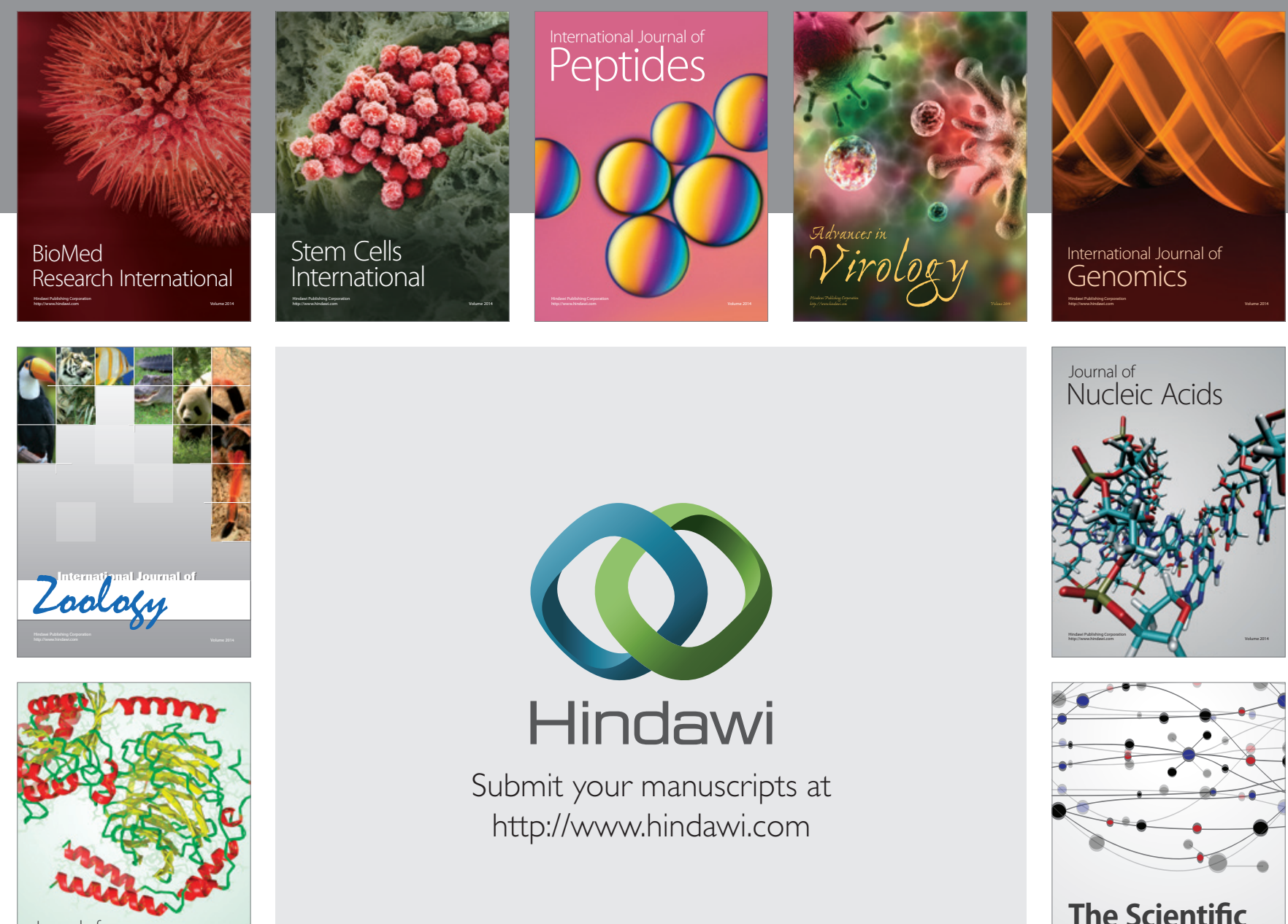

Submit your manuscripts at

http://www.hindawi.com

Journal of
Signal Transduction
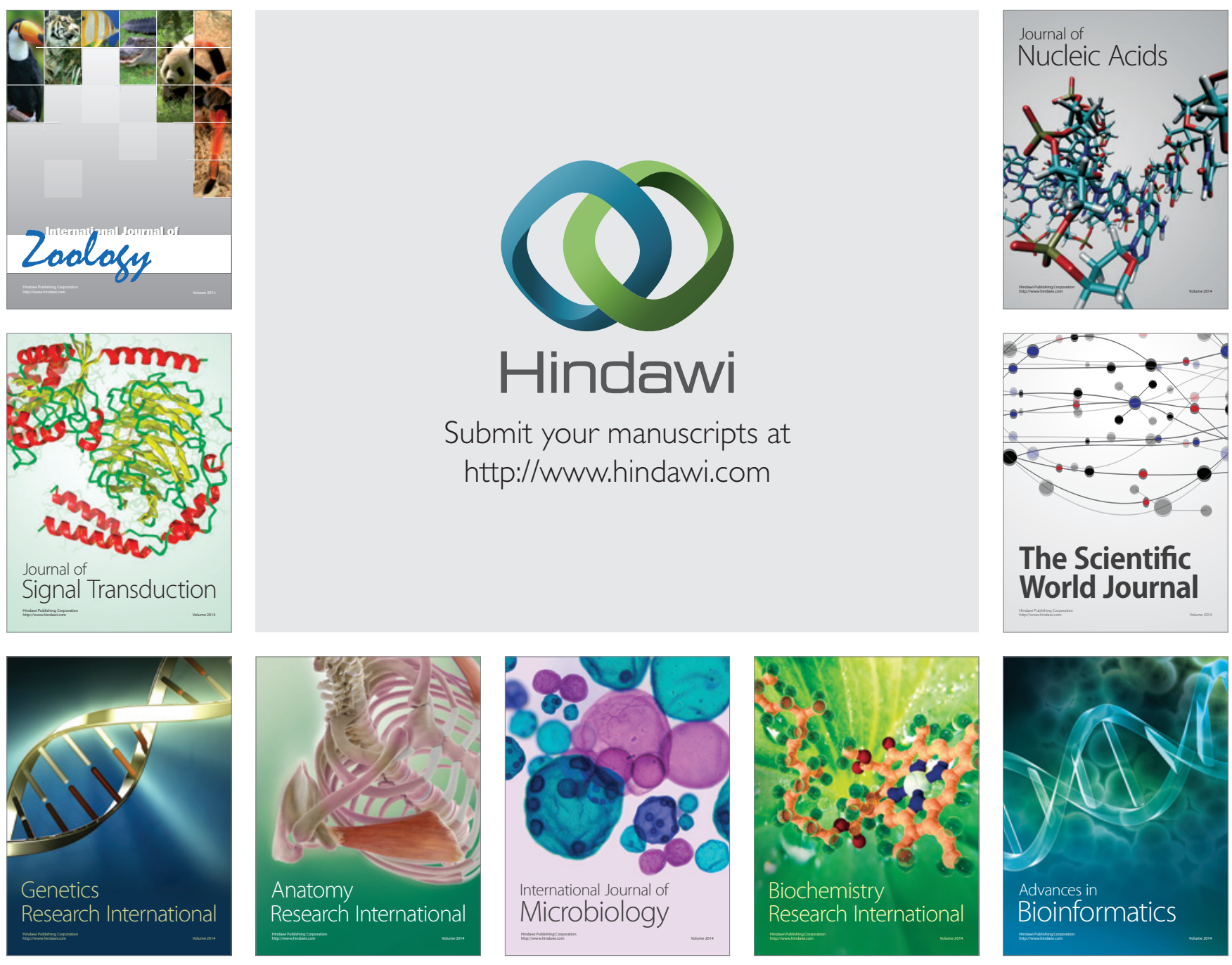

The Scientific World Journal
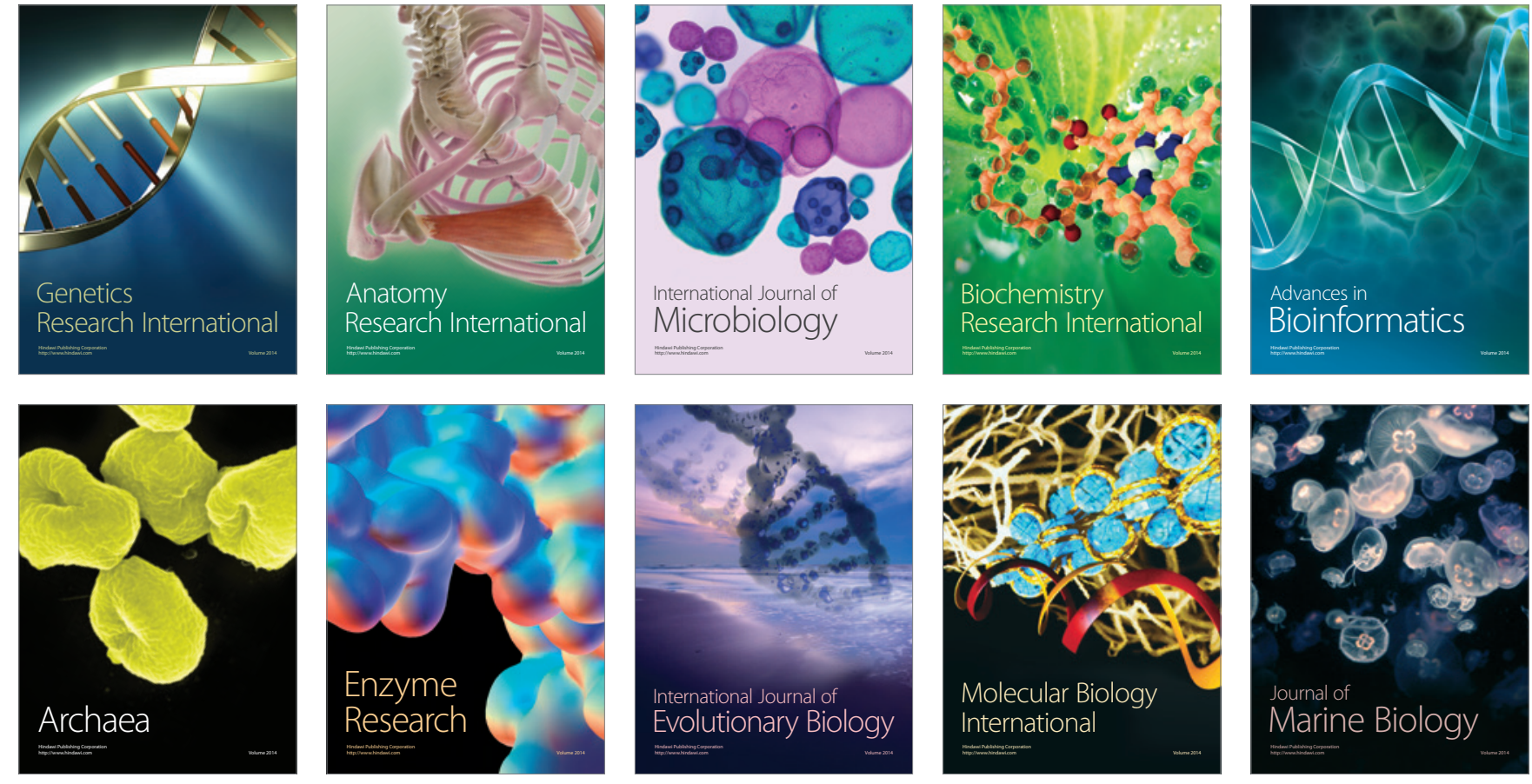